\title{
The wound healing effect of four types of beta-glucan
}

\author{
Gayoung Seo ${ }^{1}$, Changlim Hyun ${ }^{1}$, Seungin $\mathrm{Choi}^{2}$, Young Mee Kim ${ }^{1}$ and Moonjae Cho ${ }^{1 *}$
}

\begin{abstract}
Beta-glucans, which existed in the cell walls of cereals, bacteria, and fungi, comprise a group of $\beta$-D-glucose polysaccharides. We investigated the effects of four kinds of beta-glucan, that are derived from barley, yeast, mushroom, and euglena on wound healing. The migration and viability of keratinocyte or fibroblast were analyzed using the in vitro scratch wound healing assay, invasion assay, MTT assay, and in vivo assay. All the beta-glucans had a significant effect on keratinocyte migration at $20 \mu \mathrm{M}$ and showed no toxicity on dermal fibroblast. Moreover, treatment of keratinocytes with the beta-glucan derived from the mushroom (Schizophyllum commune) promoted in vivo wound closure. The Integrin/FAK/Src pathway is known to affect cell migration by forming lamellipodia. Beta-glucan from S. commune activates the Integrin/FAK/Src signaling pathway in a time-dependent. Reactive oxygen species are associated with fibroblast differentiation to contract dermal layer and synthesize collagens. We found that fibroblast was activated by increasing NOX4 expression. We propose that beta-glucan derived from mushroom is capable of promoting keratinocyte migration via the induction of FAK/Src phosphorylation there by accelerating wound closure and activating dermal fibroblast differentiation through NADPH oxidase for matrix remodeling.
\end{abstract}

Keywords: Beta-glucan, Fibroplasia, Re-epithelialization, Wound healing

\section{Introduction}

Beta-glucan is a generic term for $\beta$-D-glucose polysaccharides, a major component of the cell walls, and classified into microbial- or plant derived-glucans depending on sources such as, bacteria, fungus, yeast, cereal $[1,2]$. In general, beta-glucans have D-glucose units with $\beta-1,3$ link, but cereal beta-glucan contain both $\beta-1,3$ and $\beta-1,4$ backbone bonds. Yeast and fungus $\beta$-glucan contains long $\beta-1,6$ and short $\beta-1,6$ branching respectively, while bacterial beta-glucan have no branching [3] (Fig. 1). Also, different types of beta-glucans exhibit distinct molecular weights, solubility, and viscosity causing diverse physiological functions [4]. It is well known that beta-glucans modulate immune functions such as phagocytosis, have anti-cancer and anti-biotic properties, and lower blood pressure or cholesterol levels [5]. Since beta-glucan also induces the production of growth factors essential for skin, promotes collagen biosynthesis, and maintains

\footnotetext{
*Correspondence: moonjcho@jejunu.ac.kr

1 Jeju National University, Jeju, Republic of Korea

Full list of author information is available at the end of the article
}

skin's moisture and elasticity, we investigated whether beta-glucan regenerates damaged skin and different types of beta-glucan have different effects.

Regeneration of impaired skin involves complex biological processes, such as re-epithelialization and fibroplasia. During re-epithelialization, epithelial cells surrounding wound margin grow and migrate to form normal epidermis before they start to differentiate for stratification giving rise to the basal, spinous, granular, and cornified layers. Integrin-induced FAK/Src signaling pathway was shown to regulate epithelial cell migration [6]. For fibroplasia, it is essential that dermal fibroblast proliferates and differentiates. Differentiated dermal fibroblast synthesizes extracellular matrix, such as a collagen and elastin, and induce dermal contraction [7].

In this study, we show that four types of beta-glucan promote epithelial migration and dermal activation without any toxic effects on the skin cells. In particular, betaglucan derived from $S$. commune was most effective in wound repair. It accelerated re-epithelialization through integrin/FAK/Src signaling pathway and activated dermal 


\begin{tabular}{|c|c|c|}
\hline$\beta$-glucan type & Structure & Description \\
\hline Bacterial & & $\begin{array}{l}\text { Linear } \beta 1,3 \text {-glucan } \\
\text { (i.e. Euglena gracilis) }\end{array}$ \\
\hline Fungal & & $\begin{array}{l}\text { Short } \beta 1,6 \text { branched } \beta 1,3 \text {-glucan } \\
\text { (i.e. Schizophyllum commune) }\end{array}$ \\
\hline Yeast & & $\begin{array}{c}\text { Long } \beta 1,6 \text { branched } \beta 1,3 \text {-glucan } \\
\text { (i.e. Black yeast) }\end{array}$ \\
\hline Cereal & & $\begin{array}{c}\text { Linear } \beta 1,3 / 1,4 \text {-glucan } \\
\text { (i.e. Barley) }\end{array}$ \\
\hline
\end{tabular}

Fig. 1 The structure and description of four kinds of beta-glucans

transformation via integrin or reactive oxygen species (ROS) production.

\section{Materials and methods Materials}

Beta-glucan derived from black yeast, barley, and euglena gracilis were respectively purchased from TCI chemicals (G0331), SIGMA (G6513), and SIGMA (89862). Betaglucan derived from $S$. commune was obtained from QUEGEN biotech. These were dissolved in distilled water and adjusted to $\mathrm{pH}$ 7.0.

\section{Cell culture}

Human dermal fibroblasts were isolated from human foreskin specimens in this lab, and described in previous paper [8]. Human spontaneously immortalized keratinocyte cell lines $(\mathrm{HaCaT})$ were obtained from the Korea Cell Line Bank. HaCaT keratinocyte and primary human dermal fibroblast were cultured in DMEM (Gibco Co.) supplemented with $10 \%$ FBS (Omega Co.) and $1 \%$ penicillin/streptomycin. Cells were incubated at $37^{\circ} \mathrm{C}$ in $5 \%$ CO2.

\section{MTT assay}

Cells $\left(2 \times 10^{4}\right.$ cells $\left./ \mathrm{ml}\right)$ were seeded in 96 -well plates. Next day, cells were treated with four types of betaglucans $(0-40 \mu \mathrm{g} / \mathrm{ml})$ or $S$. commune-derived glucan $(0-0.4 \mathrm{mg} / \mathrm{ml})$. After incubation for 24 or $48 \mathrm{~h}$ with $\mathrm{HaCaT}$ or fibroblast, $10 \mu \mathrm{l}$ of MTT solution $(5 \mathrm{mg} / \mathrm{ml})$ was added to each well, and cells were incubated for an additional $4 \mathrm{~h}$ at $37^{\circ} \mathrm{C}$. The medium was replaced with $150 \mu \mathrm{l}$ DMSO, and the plate was incubated for $30 \mathrm{~min}$ at room temperature with shaking. Absorbance was measured at $570 \mathrm{~nm}$ using a spectrophotometer [9].

\section{Scratch wound healing assay}

$\mathrm{HaCaT}$ cells were incubated in 48-well plates at a density of $7 \times 10^{4}$ cells/well for $24 \mathrm{~h}$. A scratch was made on the cell monolayer by drawing a pipette tip across the well. The culture medium was supplemented with four types of beta-glucan or $S$. commune-derived-glucan dosedependently. At $0 \mathrm{~h}$ and $24 \mathrm{~h}$ post-treatment, wound closure was captured using an Olympus IX70 microscope equipped with a digital camera at $40 \times$ magnification. The distance migrated was measured using the Image J software, and calculated by comparing the initial and final width of the scratch.

\section{Matrigel invasion assay}

$\mathrm{HaCaT}$ cells $\left(7 \times 10^{4}\right.$ cells/well $)$ were seeded in the insert of a 12-well invasion assay kit (SPL Co.), and the bottom chamber was filled with media. The membrane allows the exchange of media during incubation. After $24 \mathrm{~h}$, media containing S. commune-derived glucan was added to the insert and bottom for $24 \mathrm{~h}$. Cells on the upper side of the insert were removed using a cotton swab, and cells on the lower side of the insert were fixed with $4 \%$ formaldehyde. After washing with PBS two times, invaded cells were stained with a $1 \%$ crystal violet solution and photographs were acquired at a $4 \times$ magnification using an Olympus IX70 microscope. Invasive ability was measured using the ImageJ program.

\section{Western blot}

$\mathrm{HaCaT}$ or fibroblast cells were seeded at a density of $1 \times 10^{5}$ each on $100 \mathrm{~mm}$ cell culture dishes and incubated for $24 \mathrm{~h}$. These were treated with $20 \mu \mathrm{g} / \mathrm{ml}$ of $S$. commune-derived glucan in a time-dependent manner. Total protein was extracted from treated cells using RIPA buffer, and the protein concentration was determined using the BCA Protein Assay Kit. Equal amounts of protein $(\sim 20 \mu \mathrm{g} /$ lane $)$ were analyzed from each sample by resolving with $10 \%$ sodium dodecyl sulfate-polyacrylamide gel electrophoresis (SDS-PAGE). Protein loaded gels were transferred to NC membranes, and these were blocked in 5\% skimmed milk with Tris-buffered saline 
Tween 20 (TBST) buffer, followed by overnight incubation with primary antibodies at $4{ }^{\circ} \mathrm{C}$. Cytokeratin 10 (sc53252), Cytokeratin 14 (sc-17104), FAK (sc-1688), p-FAK (sc-11765), C-Src (sc-130124), Integrin $\alpha 3, \alpha 5, \alpha 6, \alpha v, \beta 1$, $\beta 5$, and GAPDH (sc-25778) antibodies were purchased from Santa Cruz Biotechnology (USA);S100A4 (ab27957) antibody was purchased from ABcam (UK); Slug (\#9585), E-cadherin (\#3195), and p-Src (\#2101) antibodies were purchased from Cell Signaling Technology (USA). NOX4 (NB110-58849) and MMP-1 (\#444209) antibodies were purchased from Novus Biologicals and Calbiochem, respectively. We used HRP-conjugated anti-mouse (K0211589, KOMABIOTECH), anti-rabbit (K021178, KOMABIOTECH), and anti-goat (AP1079P, Millipore) as secondary antibodies. Proteins were detected using chemiluminescent reagent, ECL solution (W6002, Biosesang).

\section{In vivo experiments}

Six-week old male ICR mice ( $\mathrm{n}=6$ for each group) were chosen for the experiment. All procedures were approved by the Animal Care and Use Committee at Jeju National University (permission number 2015-0033). First, the fur was removed with an electronic hair clipper and removal cream. Then, wounds were made on the middle of the back using a 6-mm biopsy punch. Wounds of mice in the experimental group were treated daily with $200 \mu \mathrm{l}$ of beta-glucans $(200 \mu \mathrm{g} / \mathrm{ml})$ dissolved in butylene glycol for 2 weeks. Madecassol ${ }^{\circledR}$ was used as a positive control and applied to wound sites in the same manner as betaglucans. Images were captured at $0,3,7,14$ days after wounding to evaluate wound closure and the rate was calculated as a relative percentage of the original wound area, using the Image J program. At 7 days post-wound, skin tissue was isolated and fixed using a $4 \%$ formaldehyde solution. Paraffin-embedded tissues were cut into 4-mm sections and stained using Hematoxylin-Eosin.

\section{Statistical analysis}

GraphPad Prism 6 software was used for statistical analysis. Data are expressed as mean value with standard errors from three independent experiments. Significance between more than two groups was analyzed using oneway ANOVA, and the Student $t$ test was assessed to compare two groups. A P value $<0.05$ considered statistically significant.

\section{Results}

Four types of beta-glucan promote epithelial cell migration

First, we prepared four kinds of beta-glucan solutions (pH 7.0) (Fig. 1). To analyze whether four types of betaglucan, derived from S. commune, black yeast, barley, and euglena, affect the skin cell viability and migration, and have different properties, we treated $\mathrm{HaCaT}$ keratinocytes or dermal fibroblasts with various beta-glucan concentration $(0-40 \mu \mathrm{g} / \mathrm{ml})$. We found that all the betaglucans display no toxicity for $\mathrm{HaCaT}$ and fibroblast cells using an MTT assay (Fig. 2a, c). But, migrations of $\mathrm{HaCaT}$ keratinocyte were increased upon stimulation with beta-glucans and peaked at $20 \mu \mathrm{g} / \mathrm{ml}$ for all the tested beta-glucans (Fig. 2b). HaCaT cell lysates were treated with $20 \mu \mathrm{g} / \mathrm{ml}$ of beta-glucans to investigate the molecular mechanism of beta-glucan action. It was found that phosphorylation of FAK (Y397) and Slug expression sere significantly increased by $S$. commune-derived-betaglucan (Fig. 2d). As the FAK signaling pathway and transition to mesenchymal cell are major factors of wound healing, these data indicate that the four types of betaglucan have positive effects on wound repair. Especially, S. commune, beta-glucan is more effective than others.

\section{Beta-glucan derived from the mushroom (S. commune) is most effective on epithelial cell motility}

Based on the previous results, we selected the S. commune beta-glucan for further treatments. It displayed no cytotoxicity for the $\mathrm{HaCaT}$ and fibroblast cells (Fig. 3a, d), but migration of $\mathrm{HaCaT}$ cells was significantly increased at $20 \mu \mathrm{g} / \mathrm{ml}$ treatments (Fig. 3b). Invasion ability of $\mathrm{HaCaT}$ cells was enhanced by beta-glucan (S. commune) and peaked at $20 \mu \mathrm{g} / \mathrm{ml}$ (Fig. 3c). Both the migration or invasion assays are important methods to detect whether beta-glucans have an effect on wound repair. However, it is known that these assays have different actions. Invasion assay includes protrusion formation and matrix degradation and it is analyzed by staining the cells penetrating through pores. Whereas, migration assay is the way to measure the distance over which the cells migrated. Therefore, we used $20 \mu \mathrm{g} / \mathrm{ml}$ of the S. commune beta-glucan for further experiments. Interestingly, the migration was decreased at $80 \mu \mathrm{g} / \mathrm{ml}$ and rebounded again at $200-400 \mu \mathrm{g} / \mathrm{ml}$. Because the beta-glucan sample contains lots of factors that occur various biological reactions and we are not yet analyze and characterize the components of beta-glucan, we guess it came from complicated reaction (Fig. 3b). More research is needed.

\section{Mechanisms of action of the S. commune beta-glucan on epithelial and dermal fibroblast cells}

To investigate the migration mechanism of $\mathrm{HaCaT}$ cell treated with beta-glucan, we performed time-dependent treatments. Integrin is well known as a cell surface adhesion receptor, which acts upstream of the FAK/Src pathway. It has 24 subtypes which are formed by different combinations of one of the $18 \alpha$ subunits and one of the $8 \beta$ subunits, which are non-covalently assembled 


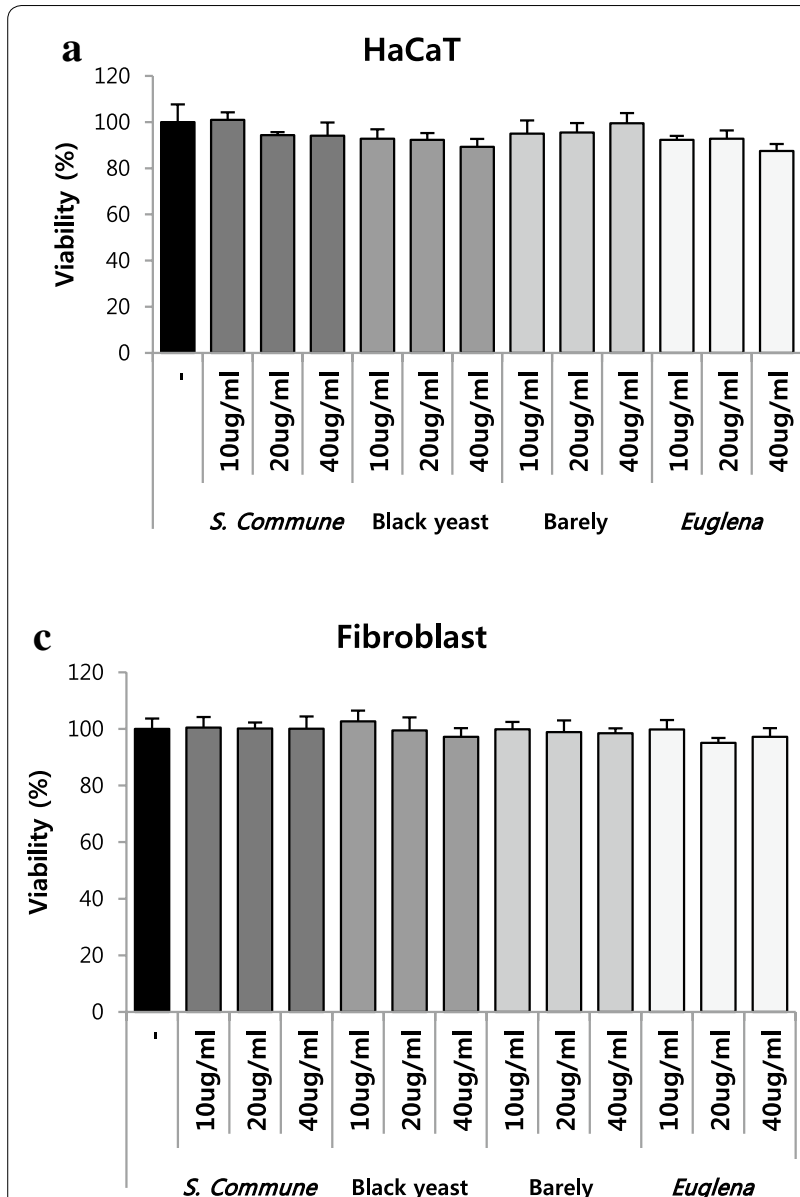

Fig. 2 The comparision of four types of beta-glucans in structure and effect on skin cells. a Viabilty of HaCaT and c fibroblast treated with beta-glucans derived from S. commune, black yeast, barely, and euglena. The cells $\left(2 \times 10^{4} \mathrm{cell} / \mathrm{s} / \mathrm{ml}\right)$ were seeded and treated with $0-40 \mu \mathrm{g} / \mathrm{ml}$ beta-glucan for $24 \mathrm{~h}$. Viability of cells was measured using the MTT solution $(5 \mathrm{mg} / \mathrm{ml})$. b Scratch wound healing assay with HaCaT treated as described in a after $24 \mathrm{~h}$. HaCaT cells $\left(7 \times 10^{4}\right.$ cells/well) were seeded on 48 well plate and a scratch was made on the cell monolayer by drawing a pipette tip across the well, and then treated with $0-40 \mu \mathrm{g} / \mathrm{ml}$. Migration distance was measured using the Image program. ${ }^{*} \mathrm{P}<0.05$ as compared to the control. $\mathbf{d}$ Western blotting for HaCaT cells treated with four types of beta-glucans. Cell lyastes were isolated using RIPA solution and protein concentration was measured by BCA assay. Phospho-FAK, E-cadherin, and slug expression were measured and their levels were normalized to $G A P D H$. The values indicate intensities of protein expression with respect to that of the loading control
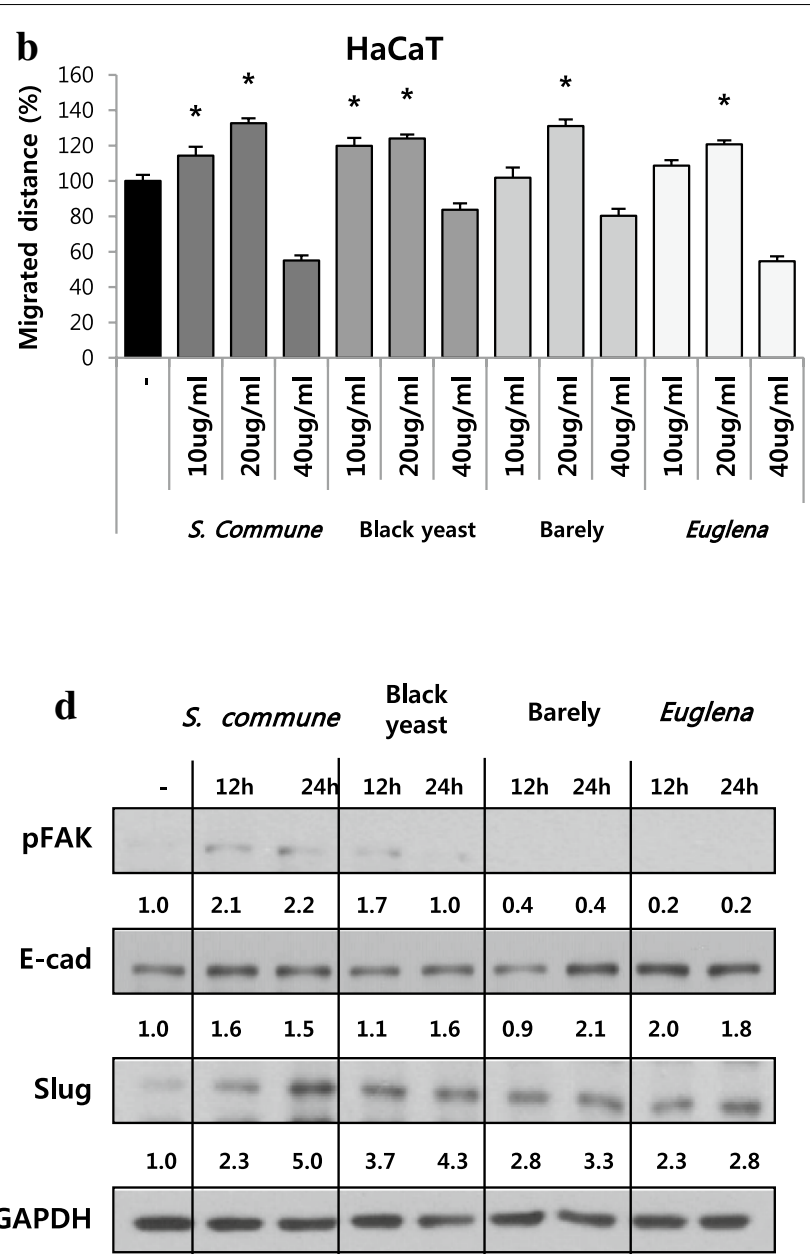

together to form heterodimer [10]. Integrin $\alpha 3 \beta 1$ mediates keratinocyte polarization during re-epithelialization and it is also known to control TGF- $\beta$ related responses [11]. Integrin $\alpha 5 \beta 1$ promotes keratinocyte migration [12] and $\alpha v \beta 1$ integrins function to regulate keratinocyte adhesion during epithelial regeneration [13]. We analyzed expression of integrin subunits in the beta-glucan treated $\mathrm{HaCaT}$ keratinocyte and found that integrin $\alpha 3 \beta 1$ and $\alpha 5 \beta 1$ were induced by the $S$. commune beta-glucan. However, the expressions of integrin $\alpha 6$ and $\alpha v$ were not affected by beta-glucan stimulation (Fig. 4a).

Focal adhesion kinase (FAK) and steroid receptor coactivator (c-Src) mediate cytoskeletal dynamics and cell motility by controlling actin polymerization [9]. 


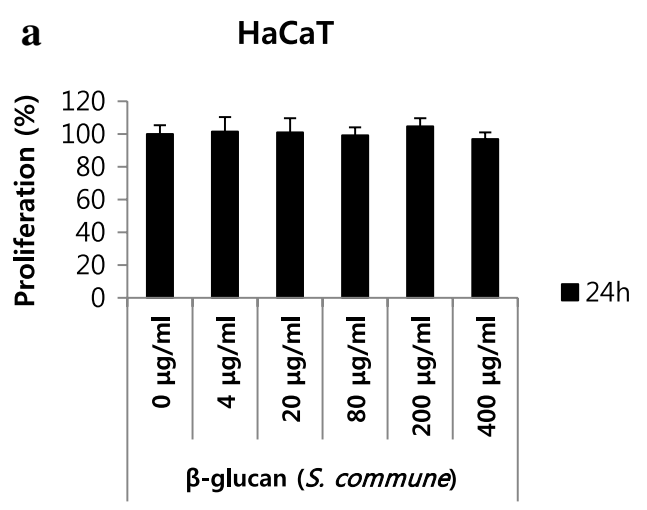

c

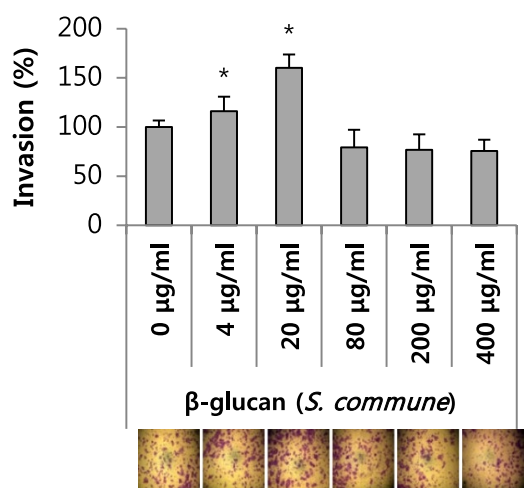

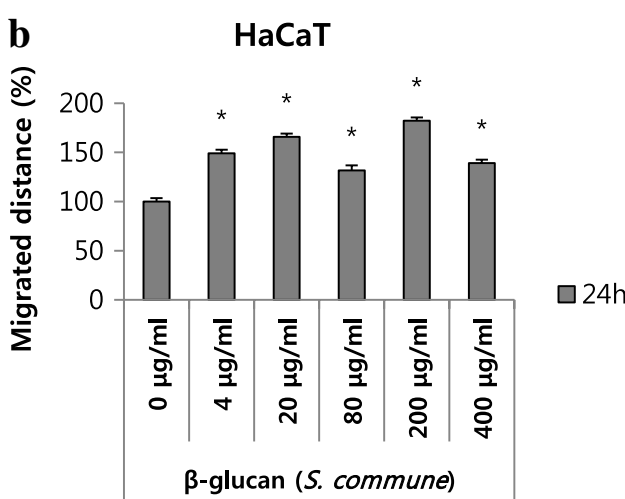

d

Fibroblast

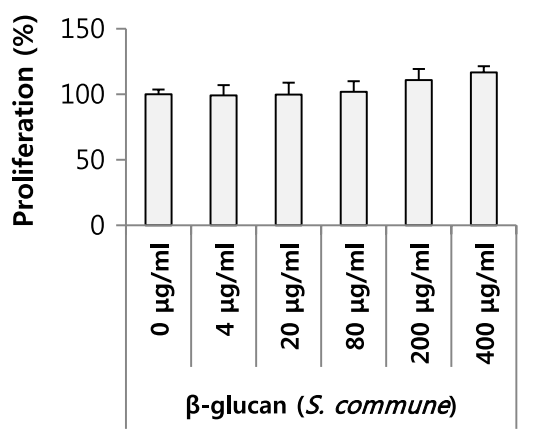

Fig. 3 The stimulation effect of beta-glucan derived from S. commune on keratinocyte migration. a Viability of HaCaT and $\mathbf{d}$ fibroblast treated with beta-glucans derived from S. commune $(0-400 \mu \mathrm{g} / \mathrm{ml})$. The cells $\left(2 \times 10^{4} \mathrm{cell} / \mathrm{s} / \mathrm{ml}\right)$ were seeded and treated with $0-40 \mu \mathrm{g} / \mathrm{ml}$ for $24 \mathrm{~h}$. Viability of cells was measured using the MTT solution $(5 \mathrm{mg} / \mathrm{ml})$. b Scratch wound healing assay with HaCaT treated as described in a after $24 \mathrm{~h}$. HaCaT cells $\left(7 \times 10^{4}\right.$ cells/well) were seeded on a 48 well plate and a scratch was made on the cell monolayer by drawing a pipette tip across the well. Migration distance was measured using the Image J program. ${ }^{*} \mathrm{P}<0.05$ as compared to the control. c Transwell invasion assay with HaCaT cells treated with beta-glucans derived from S. commune. Invasive ability was measured by fixing with $4 \%$ of formaldehyde and staining with a $1 \%$ crystal violet solution. The photographs were acquired at $\times 4$ magnification using a microscope. ${ }^{*} \mathrm{P}<0.05$ as compared to the control

Besides Integrin/FAK/Src, epithelial-mesenchymal transition (EMT) or matrix metalloproteinase (MMP) are known to be associated with cell migration [16]. However, there are no detectable changes in these pathways such as down-regulation of E-cadherin and up-regulation of Slug or MMP-1 (Fig. 4c). These data indicate the improvement of keratinocyte stimulated by the $S$. commune beta-glucan through Integrin $\alpha 3 \beta 1, \alpha 5 \beta 1 /$ FAK/Src activation.

ROS mainly function in a normal wound healing response, especially in dermal fibroblasts. Furthermore, NADPH oxidase (NOX) family is an important source of ROS generation [17]. For example, Sampson et al. demonstrated the ROS signaling by NOX4, which induces fibroblast transformation of myofibroblast by increasing phosphorylation of JNK. NOX4 coordinated cytoskeletal remodeling and differentiation [18]. The S. commune beta-glucan mostly promoted NOX4 synthesis at $24 \mathrm{~h}$ treatment (Fig. 4d).

Integrins are also required for fibroblast infiltration into wound site. Integrin $\alpha v \beta 5$, one of the integrin subunits, participates in fibroblast transformation to myofibroblast, which is marked with FSP-1, leading to dermal contraction. Upon a time-dependent treatment of fibroblasts with the $S$. commune, the expression of integrin $\alpha v \beta 5$ was increased and peaked at $48 \mathrm{~h}$ (Fig. 4e). As a result, the $S$. commune beta-glucan accelerated dermal differentiation via integrin $\alpha v \beta 5$ and ROS production.

\section{Wound healing effect of beta-glucans in the in vivo excisional wound model}

The fast wound closure occurs by epithelial regeneration following dermal remodeling. In an in vivo experiment, we made a wound using biopsy punch and measured 


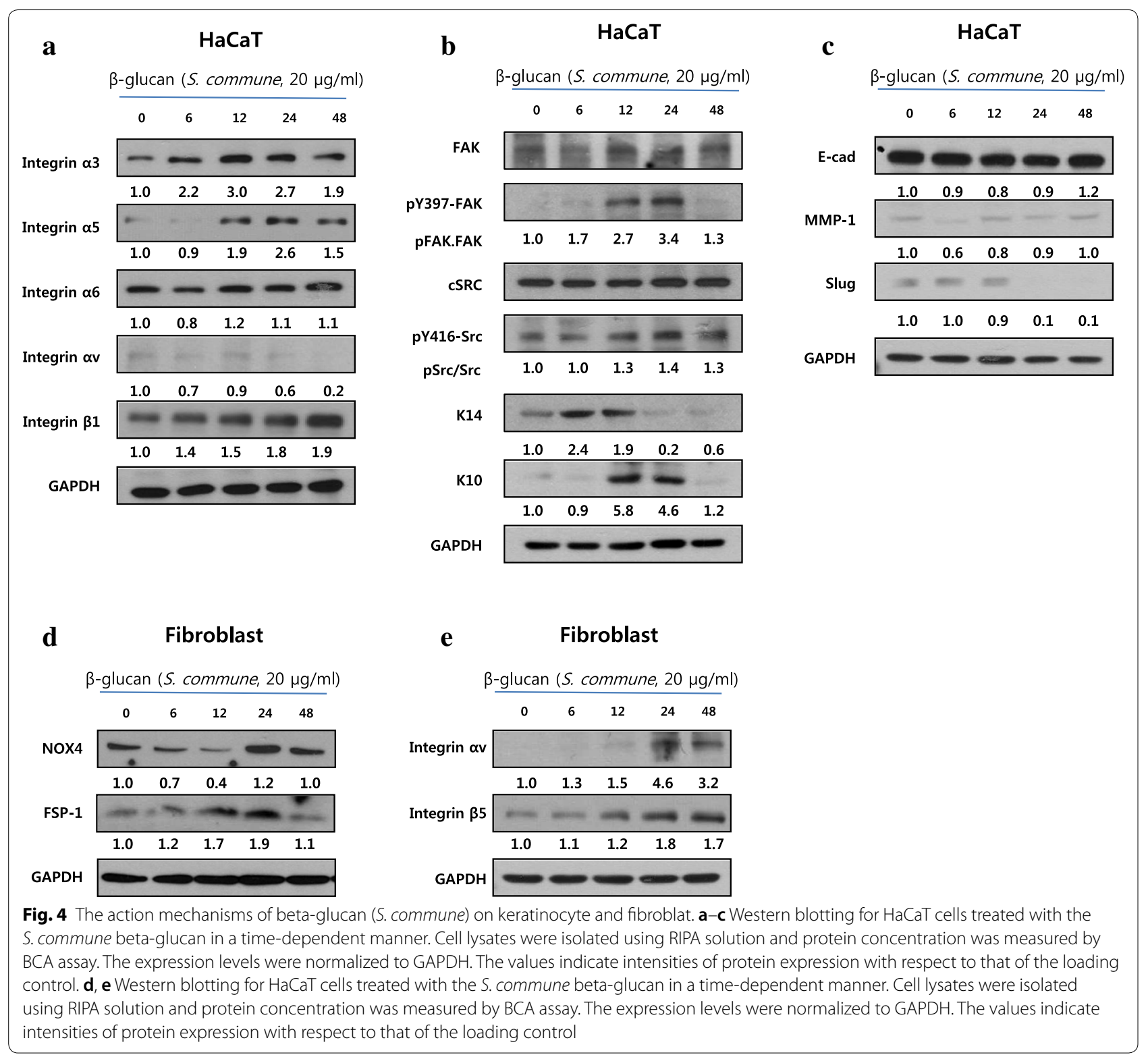

the margin area at different time points. At day 3 after wounding, there is no significant difference between groups. However, the wound closure of S. communetreated-group was accelerated in proliferative phase (Fig. 5a, b). Scab, formed during hemostasis, is a fibrin clot. As epithelial cell grows and migrates, scab loss occurs and it was used to compare the healing capacity [19]. Except for the control and black yeast-treated groups, scab began to fall apart from wound at day 8 after wounding. Scab loss in the S. commune-treated-group

(See figure on next page.)

Fig. 5 The wound healing effect of beta-glucans in an in vivo excisional model. a, b Wound closure in an excisional wound model for 14 days. Photos were taken every 3 days and wound area was measured using the ImageJ program. 'Madecassol' was used as a positive control. c The number of scab loss at day 8 after wounding. The number of scab uncombined mouse were counted and quantifiably shown as a graph ( $n=6$ each group). $\mathbf{d}$ Hematoxylin and eosin staining of skin tissue isolated from the wound site on day 7 . The photographs were acquired at $\times 100$ magnification using a microscope. Re-epithelialization was measured using the ImageJ program and showed as a graph. Dotted line; a boundary line of wound site, GT granulation tissue. ${ }^{*} \mathrm{P}<0.05$ as compared to the control 


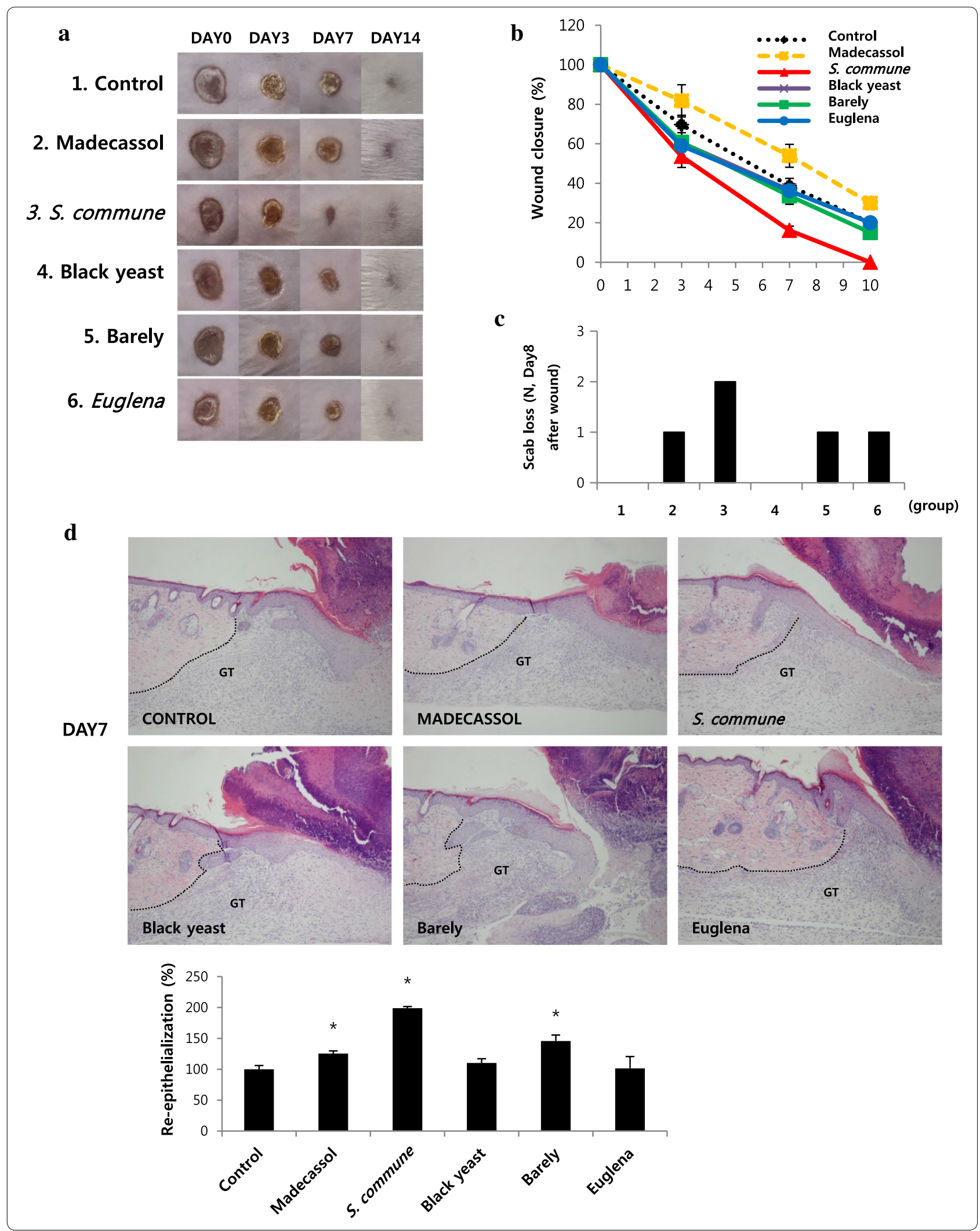


was twice as much compared to other groups (Fig. 5c). After completion of wound healing, we stained using hematoxylin and eosin using isolated skin tissue. As shown in Fig. 5d, re-epithelialization is in progress under scars at day 7. The S. commune-treated-group showed elongated and thinly-formed epithelium compared to other groups. These results indicate that beta-glucan derived from S. commune has a beneficial wound healing effect.

\section{Discussion}

Our study demonstrates that beta-glucan from $S$. commune accelerates cutaneous wound healing. Beta-glucans have a common backbone, $\beta$-1,3-glucan, which is a key factor in determining their function. The length and number of branched chains is also important for specific binding to cells of the immune system [20]. Beta-glucans are also known to promote resistance to viral, bacterial, and fungal diseases, as well as exhibit antitumor effects. In particular, beta-glucans derived from mushrooms have multiple short branches. Additionally, it is known that mushroom extract contains other effective ingredients of potential nutritional value (Fig. 1) [21]. However, the wound healing effect of beta-glucans and their roles in repairing skin injury have not been comprehensively studied.

Because of their wound healing properties, beta-glucan have been used in the development of bioartificial skin, considering their ability to bind to gelatin and collagen. It is known that wound dressing with beta-glucan enhance wound healing and reduce pain. Furthermore, beta-glucans increase proliferation, produce diverse cytokines, and release ROS in dermal fibroblast cells, leading to neutrophil infiltration and angiogenesis [22]. Here, we found that $S$. commune beta-glucan promotes dermal contraction by inducing the expression of NOX4 (which contributes to ROS generation) and Integrin $\alpha v \beta 5$ (Fig. 4).

There are four different pattern recognition receptors (PRRs) for beta-glucans in immune system cells, complement receptor 3 (CR3), scavenger receptor, lactosylceramide, and dectin-1 [23]. The dectin-1 beta-glucan receptor, has two isoforms the full-length isoform $\mathrm{A}$ and the stalk region-lacking isoform $\mathrm{B}$. A previous study by Linda et al., showed that dectin-1 isoform B is expressed in $\mathrm{HaCaT}$ keratinocytes and possesses functions which are different from the ones observed in the immune system cells. These functions include promoting proliferation and migration, which are major processes during re-epithelialization [22]. Spleen tyrosine kinase (Syk) is a mediator of dectin-1 activation and is phosphorylated by beta-glucans [24]. Syk is phosphorylated by active Src, thereby induces cell spreading. On the contrary, active Syk promotes Integrin $\alpha \mathrm{V}$ translocation to the membrane of epithelial cells and control migration through FAK and Src [25].

As shown by these reports, several receptors can recognize beta-glucans epithelial cells, with beneficial effects for wound repair. We found that S. commune beta-glucan induces FAK/Src pathway activation via integrin upregulation in $\mathrm{HaCaT}$ keratinocyte cells. In addition to the Integrin/FAK/Src pahtway, there are several indications of other action mechanisms by which $S$. commune beta-glucan may promote wound healing. One possibility is that dectin-1 and integrins stimulated by beta-glucans phosphorylate Src or Syk, forming a positive loop between them that can promotes cell migration. Further experiments are needed to prove this hypothesis.

We demonstrated the cutaneous wound healing effects of four types of beta-glucans, and found that S. commune beta-glucan is especially efficacious in wound repair due to its ability to promote re-epithelialization and dermal contraction by activation of Integrin/FAK/Src in the epidermis as well as by dermal transformation via NOX4 expression and integrin up-regulation. These findings suggest that beta-glucan from S. commune is a potential therapeutic agent for skin injury.

\section{Authors' contributions}

GS did most of experiments except animal tissue histology. CH did histology. SC prepare and supply beta-glucan. YMK and MC plan and supervise whole experiments and edit and correct writing. All authors read and approved the final manuscript.

\section{Author details \\ ${ }^{1}$ Jeju National University, Jeju, Republic of Korea. ${ }^{2}$ Quegen Biotech Co. Ltd., Seoul, Republic of Korea.}

\section{Acknowledgements}

This work was supported by the Korea Industrial Complex Corporation through the Project Fostering the Industrial Cluster (No. RKK17008).

\section{Competing interests}

The authors declare that they have no competing interests.

\section{Publisher's Note}

Springer Nature remains neutral with regard to jurisdictional claims in published maps and institutional affiliations.

Received: 1 January 2019 Accepted: 26 March 2019

Published online: 06 April 2019

References

1. Lattimer JM, Haub MD (2010) Effects of dietary fiber and its components on metabolic health. Nutrients 2:1266-1289

2. Yun CH, Estrada A, Van Kessel A, Park BC, Laarveld B (2003) Beta-glucan, extracted from oat, enhances disease resistance against bacterial and parasitic infections. FEMS Immunol Med Microbiol 35:67-75

3. Volman JJ, Ramakers JD, Plat J (2008) Dietary modulation of immune function by beta-glucans. Physiol Behav 94:276-284

4. Lee SH, Jang GY, Hwang IG, Kim HY, Woo KS, Kim KJ, Lee MJ, Kim TJ, Lee J, Jeong HS (2015) Physicochemical properties of beta-glucan from acid hydrolyzed barley. Prev Nutr Food Sci 20:110-118 
5. Rahar S, Swami G, Nagpal N, Nagpal MA, Singh GS (2011) Preparation, characterization, and biological properties of beta-glucans. J Adv Pharm Technol Res 2:94-103

6. Zhao XK, Cheng Y, Liang Cheng M, Yu L, Mu M, Li H, Liu Y, Zhang B, Yao Y, Guo H et al (2016) Focal adhesion kinase regulates fibroblast migration via integrin beta-1 and plays a central role in fibrosis. Sci Rep 6:19276

7. Darby IA, Laverdet B, Bonte F, Desmouliere A (2014) Fibroblasts and myofibroblasts in wound healing. Clin Cosmet Investig Dermatol 7:301-311

8. Kim YM, Huh J, Lim Y, Cho M (2015) Soy isoflavone glycitin (4'-hydroxy6-methoxyisoflavone-7-D-glucoside) promotes human dermal fibroblast cell proliferation and migration via TGF- $\beta$ signaling. Phytother Res 29:757-769

9. Sophors P, Kim YM, Seo GY, Huh JS, Lim Y, Koh DS, Cho M (2016) A synthetic isoflavone, DCMF, promotes human keratinocyte migration by activating Src/FAK signaling pathway. Biochem Biophys Res Commun 472:332-338

10. Lambert AW, Ozturk S, Thiagalingam S (2012) Integrin signaling in mammary epithelial cells and breast cancer. ISRN Oncol 2012:493283

11. Reynolds LE, Conti FJ, Silva R, Robinson SD, lyer V, Rudling R, Cross B, Nye E, Hart IR, Dipersio CM, Hodivala-Dike KM (2008) Alpha3beta1 integrincontrolled Smad7 regulates reepithelialization during wound healing in mice. J Clin invest 118:965-974

12. Chen WW, Tjin MS, Chua AWC, Lee ST, Tay CY, Fong E (2017) Probing the role of integrins in keratinocyte migration using bioengineered extracellular matrix mimics. ACS Appl Mater Interfaces 9:36483-36492

13. Koivisto L, Heino J, Hakkinen L, Larjava H (2014) Integrins in wound healing. Adv Wound Care (New Rochelle) 3:762-783

14. Baillat G, Siret C, Delamarre E, Luis J (2008) Early adhesion induces interaction of FAK and Fyn in lipid domains and activates raft-dependent Akt signaling in SW480 colon cancer cells. Biochim Biophys Acta 1783:2323-2331
15. Fuchs E (1994) Epidermal differentiation and keratin gene expression. Princess Takamatsu Symp 24:290-302

16. Radisky ES, Radisky DC (2010) Matrix metalloproteinase-induced epithelial-mesenchymal transition in breast cancer. J Mammary Gland Biol Neoplasia 15:201-212

17. Seo GY, Lim Y, Koh D, Huh JS, Hyun C, Kim YM, Cho M (2017) TMF and glycitin act synergistically on keratinocytes and fibroblasts to promote wound healing and anti-scarring activity. Exp Mol Med 49:e302

18. Sampson N, Koziel R, Zenzmaier C, Bubendorf L, Plas E, Jansen-Durr $P$, Berger P (2011) ROS signaling by NOX4 drives fibroblast-to-myofibroblast differentiation in the diseased prostatic stroma. Mol Endocrinol 25:503-515

19. Eming SA, Martin P, Tomic-Canic M (2014) Wound repair and regeneration: mechanisms, signaling, and translation. Sci Transl Med 6:265-266

20. Chan GC, Chan WK, Sze DM (2009) The effects of beta-glucan on human immune and cancer cells. J Hematol Oncol 2:25

21. Friedman M (2016) Mushroom polysaccharides: chemistry and antiobesity, antidiabetes, anticancer, and antibiotic properties in cells, rodents, and humans. Foods. https://doi.org/10.3390/foods5040080

22. Murphy EA, Davis JM, Carmichael MD (2010) Immune modulating effects of beta-glucan. Curr Opin Clin Nutr Metab Care 13:656-661

23. van den Berg LM, Zijlstra-Willems EM, Richters CD, Ulrich MM, Geijtenbeek TB (2014) Dectin-1 activation induces proliferation and migration of human keratinocytes enhancing wound re-epithelialization. Cell Immunol 289:49-54

24. Cohen-Kedar S, Baram L, Elad H, Brazowski E, Guzner-Gur H, Dotan I (2014) Human intestinal epithelial cells respond to beta-glucans via Dectin-1 and Syk. Eur J Immunol 44:3729-3740

25. Fotheringham JA, Coalson NE, Raab-Traub N (2012) Epstein-Barr virus latent membrane protein-2A induces ITAM/Syk- and Akt-dependent epithelial migration through alphaV-integrin membrane translocation. J Virol 86:10308-11032

\section{Submit your manuscript to a SpringerOpen ${ }^{\odot}$ journal and benefit from:}

- Convenient online submission

- Rigorous peer review

- Open access: articles freely available online

- High visibility within the field

- Retaining the copyright to your article

Submit your next manuscript at springeropen.com 